\title{
The impact of ultrasound scan training on its usage among emergency personnel in Malaysian emergency departments
}

\author{
JM Noor ${ }^{1 *}$, FM Salleh ${ }^{2}$ \\ From 9th WINFOCUS World Congress on Ultrasound in Emergency and Critical Care \\ Hong Kong. 6-9 November 2013
}

\section{Background}

The use of ultrasound scan (USS) in Malaysian Emergency Departments (ED) began ten years ago but has increased exponentially over the last four years. The aim of our study is to determine the current training and usage of emergency ultrasound.

\section{Methods}

A questionnaire was distributed to 47 hospitals with Emergency Physicians (EP) in Malaysia. Questions included patient load, background on USS courses attended and frequency of ultrasound usage in clinical management.

\section{Results}

29 hospitals responded including 15 general hospitals, 11 district hospitals and 3 university hospitals. All ED has at least 1 ultrasound machine.

In general hospitals, patient load ranged between $60,000-320,000$ per year. Mean number of EPs is 4 . Mean percentage of EPs who had attended any course is $79 \%$ (SD 27.8). In 7 hospitals, 100\% had attended a course. In 1 hospital, the sole EP has not attended an USS course. The average percentage of Medical Officers (MO) who had attended an USS course is $41 \%$ (SD 17.7). In terms of frequency of USS usage, $80 \%$ cited usage of 'very often' and $20 \%$ cited 'often'.

In district hospitals, patient load varied between 45,000 $-130,000$ per year. Most EDs had at least 1 EP. Except for one EP, all had attended an USS course. 35\% of MOs had attended an USS course (SD 32.9). The frequency of use cited was $30 \%$ as 'very often' and $70 \%$ as 'often'.
Whilst in university hospitals, patient load was between $65,000-100,000$ patients per year. The mean number of EPs was 11 . An average of $53 \%$ of EPs had attended an USS course, but only $26 \%$ of MOs had attended a similar course. In terms of frequency of use, $67 \%$ cited 'very often' and $33 \%$ cited 'often'.

All agreed that USS changed their clinical management significantly.

\section{Conclusion}

Across the different hospital settings in Malaysia, all cited that USS is used 'often' and 'very often'. However, there are more EPs and MOs in general hospital that has been trained in USS compared to university setting. This is in contrast with the study in California (2009) where most ED do not use ultrasound and academic EDs used it more than community EDs. The issue now is the credentialing process is not fully determined.

\footnotetext{
Authors' details

${ }^{1}$ Faculty of Medicine, Universiti Teknologi Mara, Malaysia. ${ }^{2}$ Emergency Department, Hospital Sg Buloh, Malaysia.
}

Published: 31 January 2014

doi:10.1186/2036-7902-6-S1-A24

Cite this article as: Noor and Salleh: The impact of ultrasound scan training on its usage among emergency personnel in Malaysian emergency departments. Critical Ultrasound Journal 2014 6(Suppl 1):A24.

\footnotetext{
${ }^{1}$ Faculty of Medicine, Universiti Teknologi Mara, Malaysia

Full list of author information is available at the end of the article
}

SpringerOpen $^{\circ}$

(C) 2014 Noor and Salleh; licensee Spinger. This is an Open Access article distributed under the terms of the Creative Commons Attribution License (http://creativecommons.org/licenses/by/2.0), which permits unrestricted use, distribution, and reproduction in any medium, provided the original work is properly cited. The Creative Commons Public Domain Dedication waiver (http:// creativecommons.org/publicdomain/zero/1.0/) applies to the data made available in this article, unless otherwise stated. 